\title{
Smart working e as novas tendências no mundo do trabalho: um estudo de caso binacional
}

O processo de smart working tem crescido nos últimos anos na Europa e no mundo. Partindo da ótica que o fenômeno pode se tornar uma tendência também no Brasil, o objetivo desse trabalho consistiu em analisar o potencial de aplicabilidade, considerando variáveis, tais como: o contexto cultural do país, a cultura organizacional da filial brasileira e a legislação que regulamenta o trabalho ágil. O procedimento da investigação adotado neste estudo foi qualitativo, via pesquisa exploratória, realizada por meio da investigação e da análise documental teórica e bibliográfica do tema e complementada pelo uso de questionário. Devido à necessidade de verificar a possibilidade de estender as práticas de smart working adotadas pela matriz italiana na filial brasileira, houve a necessidade pragmática de combinar dados em uma base lógica, para melhor entendimento do fenômeno, e verificar a factibilidade nas atividades da filial. Pelas respostas oferecidas de forma voluntária pelos funcionários da empresa foi possível comparar os dados obtidos de cerca de $80 \%$ dos funcionários da matriz (115 pessoas) com $64 \%$ dos colaboradores da filial (42 pessoas). Como resultado, a análise das evidências revelou propensão à mudança em favor do trabalho ágil. Na filial brasileira, a atuação pelo método do trabalho remoto por parte dos funcionários foi bem aceita. Os dados obtidos evidenciaram pontos a melhorar na qualidade dos instrumentos de comunicação entre líderes e liderados. Concluiu-se que a nova prática trabalhista, embora represente a mudança de paradigmas, estimulará grandes mudanças e alterará o nível cultural dentro da organização como novo valor compartilhado.

Palavras-chave: Smart working; Trabalho ágil; Cultura organizacional; Diferenças culturais.

\section{Smart working and new trends in the world of work: a binational case study}

\begin{abstract}
The smart working process has grown in recent years in Europe and around the world. Starting from the perspective that the phenomenon could also become a trend in Brazil, the purpose of this work is to analyze the potential of its applicability, considering variables such as: the cultural context of the country, the organizational culture of the Brazilian branch and the legislation that regulates the agile work. The investigation procedure adopted in this study was qualitative, through exploratory research, conducted through the investigation and theoretical and bibliographic analysis of the documents on the subject and supplemented by the use of a questionnaire. Due to the need to verify the possibility of extending the Smart working practices adopted by the Italian headquarter in the Brazilian branch, there was a pragmatic need to combine data on a logical basis, to better understand the phenomenon and verify the feasibility of the branch's activities. Through the responses offered voluntarily by company employees, it was possible to compare the data obtained from approximately $80 \%$ of the employees of the headquarters ( 115 people) with $64 \%$ of the employees of the branch (42 people). As a result, analysis of the evidence revealed a propensity for change in favor of agile working. In the Brazilian branch, the applied form of remote work was well accepted by employees. The data obtained highlighted aspects for improvement regarding the quality of communication tools between leaders and followers. It was concluded that the new working practice, while representing a paradigm change, will spur major changes and change the cultural level within the organization as a new shared value.
\end{abstract}

Keywords: Smart working; Agile work; Organizational culture; Cultural differences.

Topic: Recursos Humanos

Reviewed anonymously in the process of blind peer.
Received: 09/01/2021

Approved: 21/03/2021
Elia Markovic (iD

Universidade de São Paulo, Brasil http://lattes.cnpq.br/6648593772050602

http://orcid.org/0000-0001-8273-0215

eliolone@gmail.com

Clauber de Oliveira Rossini (i)

Centro Universitário Campo Limpo Paulista, Brasil

http://lattes.cnpq.br/5498029740500744

http://orcid.org/0000-0003-0140-1714

regulusrossini@gmail.com
Referencing this:

MARKOVIC, E.; ROSSINI, C. O.. Smart working e as novas tendências no mundo do trabalho: um estudo de caso binacional. Revista Brasileira de Administração Científica, v.12, n.1, p.94-110, 2021. DOI: http://doi.org/10.6008/CBPC2179-684X.2021.001.0008 


\section{INTRODUÇÃO}

O contexto de trabalho do autor, gerente na filial brasileira de uma empresa multinacional sediada na Itália, originou a reflexão sobre a aplicabilidade das ações práticas originadas pelo recente conceito de smart working, também conhecido como trabalho ágil.

Os resultados obtidos na Europa ${ }^{1}$ em termos de produtividade e de bem-estar do trabalhador indicam a possibilidade de reprodução desse modelo no Brasil. No entanto deve ser analisada a sua aplicabilidade levando em conta a diversidade cultural, a cultural empresarial local e a estrutura legislativa brasileira. O objetivo geral desse trabalho consistiu em analisar o potencial de aplicabilidade considerando variáveis tais como o contexto cultural do país e a legislação que regulamenta o trabalho ágil.

Os objetivos específicos foram: 1 . Analisar a forma de abordagem do conceito de smart working a partir da análise dos textos que o regulamentam na Itália e no Brasil; 2. Aplicar o questionário; 3. Verificar a replicabilidade na filial brasileira das ações voltadas à realização do smart working realizadas na matriz da empresa italiana.

\section{REVISÃO TEORICA}

\section{Conceito de Smart working ou Trabalho Ágil}

Entre as várias tentativas de identificar o fenômeno do smart working, o modelo proposto por Clapperton et al. (2014) parece o mais claro. Os autores identificam no Smart working as três B, ou seja, os três elementos principais para introduzir o processo em uma empresa que são: Behaviours: os comportamentos (as condutas). O abandono dos clássicos horários do escritório e trabalho por objetivos concretos. A regra é obter os resultados previstos nos prazos prefixados, com o máximo da qualidade. Um trabalhador smart deve ser responsabilizado e educado na gestão do tempo. O elemento chave é a confiança e não o controle; Bytes: a tecnologia. Hoje as empresas podem utilizar ambientes tecnológicos favoráveis e formidáveis, frequentemente colaborativos e gratuitos; Bricks: os espaços físicos, o layout do escritório. A mentalidade colaborativa se atua de forma melhor em espaços abertos, não é importante onde trabalha-se, mas se o ambiente é confortável

A partir desse modelo, pode-se extrair quais são os quatro pilares fundamentais que identificam o conceito de smart working (HARTOG et al., 2015): 1. Revisão da cultura organizacional e dos estilos gerenciais, que implica a revisão da visão do trabalho, passando a uma definição de trabalho por objetivos (e não mais em horas trabalhadas). A confiança entre os membros toma o lugar do arcaico conceito de controle. A liderança é reinterpretada, o líder passa a ser o conselheiro e não mais o chefe e centro de todas as operações; 2. Flexibilidade de horários e locais de trabalho, se perde totalmente a rigidez da clássica visão do trabalho. A produtividade é medida através dos objetivos alcançados, da capacidade de resposta às solicitações recebidas; 3. Dotação tecnológica necessária a suportar as novas necessidades de flexibilidade

\footnotetext{
${ }^{1}$ Working anytime, anywhere: The effects on the world of work, Publications Office of the European Union, Luxembourg, and the International Labour Office, Geneva 2017
} 
do trabalhador, através do cloud, introduzindo o conceito de Bring Your Own Device (BYOD) e chegando às tecnologias imersivas que simulam a presença física em ambientes virtuais; 4. Espaços físicos, que devem ser reorganizados para as novas necessidades entrando na hera do desk sharing a escrivaninha compartilhada, e abandonando aquela visão do lugar pré-estabelecido.

\section{Os benefícios do Smart working}

É importante identificar o que comporta mudar para o smart working, Hartog et al. (2015) identificam dois benefícios/desafios fundamentais:

O crescimento dos trabalhadores como indivíduos e consequentemente da organização em que eles pertencem, de forma que aumente o engajamento do próprio trabalho. Segundo os autores, este processo passa através do desenvolvimento da motivação intrínseca, que quer abandonar os clássicos estilos de gestão baseados no controle e nas punições em favor da teoria da autodeterminação, que se baseia no cumprimento de três condições, representados pela Figura 1 (PINK, 2009): Autonomia: ou seja, a necessidade de controlar a própria vida; Domínio: a necessidade de ser bom e competente em fazer algo que importa; Significância: a necessidade de fazer algo que pertença a um projeto maior do que nós.

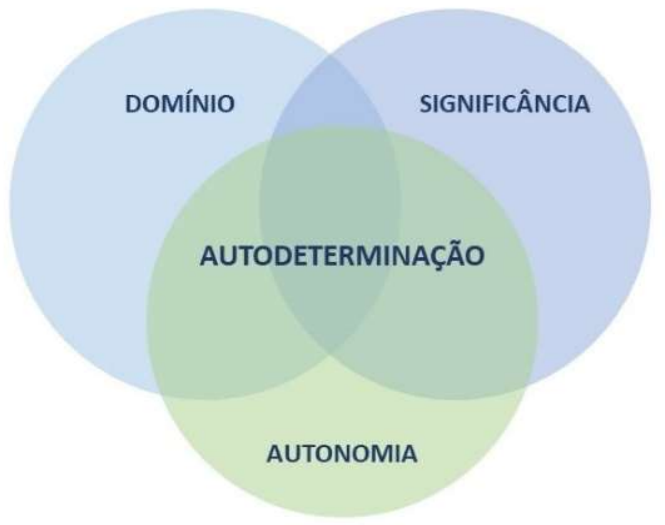

Figura 1: Os três pilares da teoria da autodeterminação. Fonte: Pink (2009).

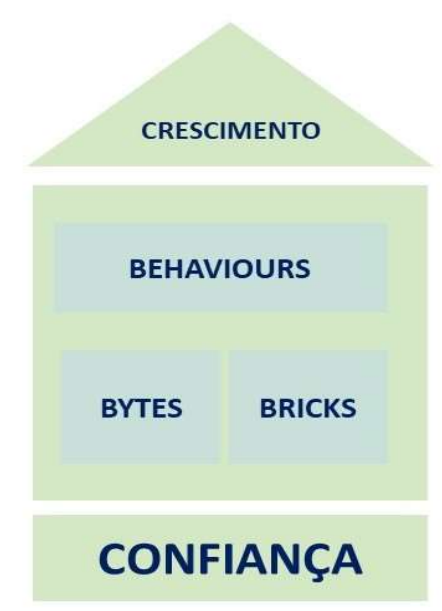

Figura 2: A confiança como base do smart working. Fonte: Hartog et al. (2015).

Encontrar o justo equilíbrio entre vida privada e vida profissional: um work-life balance ideal afeta positivamente no bem-estar do trabalhador fazendo com que se torne mais feliz e satisfeito e consequentemente mais motivado e produtivo.

Tudo isso pode ser atuado através da mudança do paradigma de gestão. Hartog et al. (2015) identificam que atualmente as empresas baseiam-se na gestão dos riscos, na redução dos erros através da aplicação de sempre mais controles e reuniões. A tendência deve se inverter: menor controle para maior confiança, que se traduz em maior autonomia e maior responsabilidade do trabalhador. A função do gestor (manager) também vai mudar: ele perde o papel de controlador e adquire um papel de conselheiro de staff. A nova base fundamental do relacionamento nas organizações é a confiança entre as partes, assim como representado na Figura 2. 


\section{Análise da regulamentação jurídica atual na Itália e no Brasil}

Na Itália em 2017, com a reforma da Legislação Trabalhista através da Lei 81 de 22/05/2017, denominada Jobs Act, foi introduzido e regulamentado no capítulo II o Trabalho Ágil objetivando inverter essa tendência. Essa reforma representa uma novidade no panorama italiano pois no primeiro artigo enfatiza-se explicitamente o escopo da reforma, que é favorecer a conciliação dos momentos de vida e de trabalho ${ }^{2}$.

No mesmo período, no Brasil, com a Reforma Trabalhista (Lei 13.467 de 13/07/2017) assistiu-se à regulamentação do teletrabalho (home office) que já era aplicado em diversas situações, mas que ainda não era abordado expressamente pela Consolidação das Leis do Trabalho (CLT). Foi criado o capítulo II-A da CLT, abordando $o$ assunto nos artigos 75-A e seguintes.

As duas reformas trouxeram novidades importantes na flexibilidade dos relacionamentos trabalhistas, transformando-as profundamente e adequando-as à tendência presente em todos os países. Este estudo procurou analisar os aspectos fundamentais dessas duas reformas, pelas caraterísticas comuns e eventuais diferenças.

A lei italiana no artigo 18 da reforma, descreve com precisão os seguintes conceitos que estão na base do trabalho ágil ${ }^{3}$ : Conciliação entre a vida privada e a vida profissional; Sem vínculos de horário; Acordo entre as partes; Sem lugar fixo (parte da atividade nas dependências da empresa e parte fora da empresa); Utilizando recursos tecnológicos; Introdução gradual, por fases.

Deixando de fora os artigos sucessivos dessa reforma que tratam prevalentemente de aspectos quais o recesso, o aviso prévio, a responsabilidade das partes, etc. e, passando a analisar os primeiros artigos da reforma brasileira, pode-se notar imediatamente a profunda diferença de abordagem do legislador, que passa diretamente a definir, no artigo 75-B, o conceito de teletrabalho, que podemos sintetizar da seguinte maneira ${ }^{4}$ : Não se faz referência à ausência dos vínculos de horário; Acordo mútuo; Preponderantemente fora das dependências do empregador; Utilizando recursos tecnológicos; Não existe referência sobre a modalidade de introdução gradual dessa forma de trabalho.

Analisando as duas leis, percebe-se uma discrepância em relação ao vínculo de lugar: enquanto a lei italiana fala somente que a prestação da atividade pode ser realizada parcialmente fora das dependências da empresa, a lei brasileira estabelece o caráter de preponderância do trabalho externo. Por tanto, enquanto a lei italiana flexibiliza totalmente a modalidade de atuação quanto e local de atividade, a lei brasileira impõe o vínculo de permanência fora do local empresarial. Assim o projeto implementado na matriz italiana que prevê que o trabalhador trabalhe da empresa um dia por semana não seria replicável na filial brasileira,

\footnotetext{
${ }^{2}$ Tradução livre de trecho do artigo 18 da Lei 81/2017

3 “...com o escopo de incrementar a competitividade e favorecer a conciliação dos momentos de vida e de trabalho, promovem (estas disposições) o trabalho ágil como modalidade de execução do relacionamento de trabalho subordinado estabelecida através acordo entre as partes, inclusive com formas de organização por fases, ciclos e objetivos e sem específicos vínculos de horários e de lugar de trabalho, com a possível utilização de instrumentos tecnológicos para o desenvolvimento da atividade de trabalho. A prestação de trabalho é executada, parcialmente nas dependências da empresa e parcialmente fora sem uma estação (de trabalho) fixa..."

4 “... prestação de serviço preponderantemente fora das dependências do empregado, com utilização de tecnologias de informação e de comunicação que, por sua natureza, não se constituam como trabalho externo."
} 
baseando-se na lei de reforma mencionada acima.

Ademais, a lei italiana deixa total liberdade na forma, podendo ser atuada por fases, ciclos e objetivos, enquanto a lei brasileira, ao contrário, parece ser mais rígida pois não prevê formas alternativas. Portanto, enquanto a lei italiana parece tentar favorecer formas inovadoras das relações de trabalho, a lei brasileira se limita a normatizar uma forma unívoca de trabalho. A Tabela 1 sintetiza quanto apenas explicitado:

Tabela 1: Confronto entre a Lei 13.467/2017 (Brasil) e a Lei 81/2017 (Itália).

\begin{tabular}{|c|c|c|c|}
\hline & Lei $\quad 13.467$ & $13 / 07 / 2017$ & $22 / 05 / 2017$ \\
\hline & Teletrabalho & & smart working \\
\hline Objetivo & $\begin{array}{l}\text { Conceituar o teletrabalh } \\
\text { local de prestação }\end{array}$ & o a partir do & $\begin{array}{l}\text { Introduzir o smart working como forma para aumentar a } \\
\text { competitividade e favorecer a conciliação entre a vida privada e a } \\
\text { vida profissional }\end{array}$ \\
\hline Vínculo de horário & $\begin{array}{l}\text { O teletrabalhador é } \\
\text { controle da jornada }\end{array}$ & excluso ao & $\begin{array}{l}\text { Nenhum vínculo nos limites da duração máxima do horário de } \\
\text { trabalho }\end{array}$ \\
\hline Local de execução & $\begin{array}{l}\text { Preponderantemente } \\
\text { dependências do empreg }\end{array}$ & $\begin{array}{l}\text { fora das } \\
\text { gador }\end{array}$ & $\begin{array}{l}\text { Parcialmente nas dependências da empresa e parcialmente fora, } \\
\text { sem estação de trabalho fixa }\end{array}$ \\
\hline $\begin{array}{l}\text { Forma de organização } \\
\text { Formalidade }\end{array}$ & $\begin{array}{l}\text { Não prevista } \\
\text { Acordo mútuo }\end{array}$ & & $\begin{array}{l}\text { Liberdade nas formas de organização por fases, ciclos e objetivos } \\
\text { Acordo entre as partes }\end{array}$ \\
\hline
\end{tabular}

\section{O covid-19 e o impulso na implementação do smart working}

A partir do início deste 2020, a difusão rápida de uma nova doença proveniente da China conhecida como Covid-195, ou simplesmente Corona Vírus, vem revolucionando a economia mundial. A rápida difusão dessa doença, que partindo da China, em pouquíssimo tempo se espalhou na Europa e em seguida no continente americano, gerou nos países reações iniciais diferentes: alguns países inicialmente tentaram minimizar a doença para não criar impacto negativo nas economias, outros imediatamente reagiram com medidas fortes em relação à prevenção e ao controle da doença. Antes ou depois, todos, enfim, chegaram a seguir as mesmas medidas baseadas na prevenção da difusão através do distanciamento social, um afastamento gradual da população através normas e medidas que limitam a circulação das pessoas.

Este cenário totalmente inesperado e urgente deu uma enorme aceleração na difusão de práticas de trabalho mais flexíveis: o trabalho remoto, o teletrabalho e também o smart working.

Na Itália, por exemplo, o Governo aprovou várias normas com a intenção de limitar a difusão e contemporaneamente ajudar os trabalhadores e as empresas nestes momentos difíceis. $O$ Decreto do Presidente do Conselho dos Ministros (DPCM) de 1 de março de 2020 o Governo italiano estabeleceu a liberdade de ativação do smart working também em ausência de acordo individual escrito por seis meses. Neste período, houve um enorme incremento de casos de em que as empresas para continuar as próprias atividades, aceleraram os processos desenvolvimento das práticas de smart working ${ }^{6}$.

No Brasil, objetivando a mesma finalidade de favorecer o processo de trabalho ágil, através da Medida Provisória 927 de 22 de março de 2020, juntamente com várias medidas para conter os efeitos negativos da pandemia nos trabalhadores e nas empresas, o capítulo II é expressamente voltado à

\footnotetext{
${ }^{5}$ Extraído do site da Organização Mundial da Saúde: https://www.who.int/emergencies/diseases/novel-coronavirus-2019/events-as-they-happen

${ }^{6}$ Em 2019 segundo os dados publicados pelo Osservatorio Smart Working do Politécnico de Milão, teve um incremento de 20\% no número de smart workers na Itália chegando a 570.000 unidades. Na situação descrita em línea teórica todas as empresas necessariamente devem adotar uma profunda aceleração para se manter ativas, com efeito de assistir a crescimentos exponenciais dos números.
} 
simplificação das normas que regulamentam o teletrabalho. Em particular é prevista mais agilidade na adoção do teletrabalho nas empresas, sem a necessidade de acordos individuais e coletivos e simplesmente notificando o trabalhador com uma antecedência de 48 horas. Claramente, enquanto provisória e valida durante o estado de calamidade pública, a medida não representa uma mudança definitiva das normas regulatórias, mas com certeza está impulsionando de forma eficaz uma transformação das estruturas organizacionais que poderá se transformar em medida definitiva e não simplesmente limitada ao momento de emergência.

O que emerge dessa situação é que o senso de urgência citado por Hartog et al. (2015) está estimulando de forma muito eficaz o change management das empresas, que estão acelerando enormemente os processos de adoção de metodologias de trabalho ágil internamente.

\section{Os contextos culturais e as culturas organizacionais nos dois Países}

Além do ambiente normativo presente nos dois países, resulta ser de grande importância a análise do ambiente cultural onde as empresas objeto de estudo, a matriz italiana e a filial brasileira, operam.

Uma grandíssima contribuição no estudo das culturas e da influência da cultura nacional nas organizações foi realizada por Hofstede et al. (1990). Através de uma pesquisa realizada nos anos 80, analisando mais de 100 mil questionários de funcionários daquela que, na época, era a maior fonte de dados em mais de 70 países, a IBM, identificou incialmente 5 dimensões que sucessivamente, através da colaboração de outros pesquisadores, passaram a ser as notórias 6 dimensões da cultura, sendo que algumas delas corroboram com aquelas elencadas por Trompenaars (1993): Distância do poder (PDI): que pode ser definida como a medida do grau de aceitação da desigualdade da distribuição do poder no sistema social; Individualismo versus coletivismo (IDV): o individualismo é a orientação principal para si mesmo. 0 coletivismo caracteriza sociedades nas quais as pessoas são integradas onde o interesse do grupo é mais forte do interesse individual; Masculinidade versus feminilidade (MAS): nas sociedades masculinas os papéis são nitidamente definidos, o homem é duro, firme e competitivo, enquanto a mulher cria e educa os filhos e se sacrifica pela carreira do marido. Nas sociedades femininas os papéis sociais dos sexos se sobrepõem; Necessidade de controle das incertezas (UAI): países com elevado índice de controle da incerteza são caracterizados pela presença de numerosas leis, normas e regras, que controlam os direitos e obrigações das pessoas, dos trabalhadores e nos relacionamentos de negócios em geral. Nos países que apresentam baixa necessidade de controle da incerteza só se estabelecem normas em casos de absoluta necessidade; Orientação de longo prazo versus orientação de curto prazo (LTO): na orientação para o curto prazo verificase o respeito pelas tradições que acaba por refletir o respeito às obrigações sociais e o apelo ao status. $\mathrm{Na}$ orientação para o longo prazo a tendência é promover a adoção de determinados comportamentos como perseverança e austeridade; Hedonismo ou Indulgence versus Restraint (IVR) 7 : na orientação indulgente a percepção é que o indivíduo é livre de agir como ele quer. Na orientação restraint, ou seja, limitada,

${ }^{7}$ Dimensão introduzida em 2010 graças à colaboração com Michael Minkov. Hofstede (2010). 
restringida, há a percepção de que as ações individuais são sujeitas a toda uma série de restrições e proibições.

A análise desenvolvida por Hofstede et al. (1990) representou um marco dos estudos das culturas organizacionais. Essas dimensões foram sucessivamente atualizadas introduzindo novos países no estudo. No Brasil, uma contribuição é representada pelo estudo conduzido por Tanure (2005), que analisa a mudança dessas dimensões individuadas por Hofstede et al. (1990) depois de décadas no Brasil e nos vários países da América Latina. A autora mostra como esses valores mudam com o tempo, sendo consequência de mudanças na sociedade ${ }^{8}$. Em uma primeira análise dos valores percebe-se que existem dimensões que ao longo do tempo tendem a se equiparar entre os dois países (LTO por exemplo). Outras, ao contrário, tendem a se afastar ou pelo menos a permanecer absolutamente distantes.

Em seguida, a Figura 3 mostra a representação dos dados obtidos nos dois estudos citados, de Hofstede et al. (1990) e Tanure (2005)

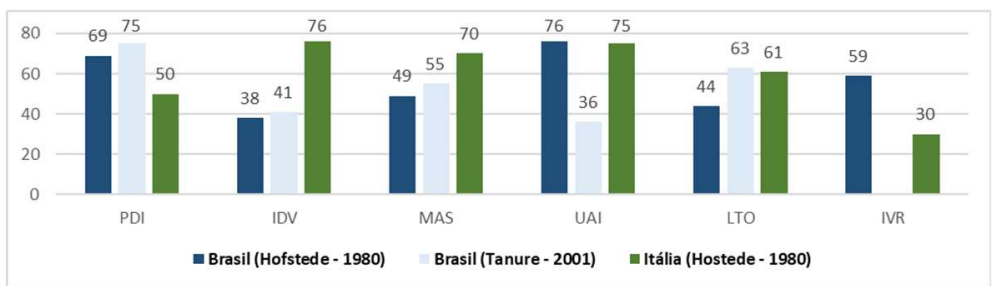

Figura 3: Dimensões culturais do Brasil e da Itália. Fonte: Hofstede et al. (1990); Tanure (2005).

Em uma primeira análise dos valores percebe-se que existem dimensões que ao longo do tempo tendem a se equiparar entre os dois países (LTO por exemplo). Outras, ao contrário, tendem a se afastar ou pelo menos a permanecer absolutamente distantes.

Através estudo dessas variáveis Tanure (2005) identifica as seguintes características do estilo brasileiro de administrar: O brasileiro tem tendencialmente uma postura do espectador: o brasileiro acostumou-se com a paternalismo, o mandonismo e o protecionismo dos líderes, o que necessariamente leva a uma atitude de baixa iniciativa, de transferência da responsabilidade e de dependência. A lógica que desencadeia é seguinte "se o poder não está comigo, não estou incluído nele e não sou eu quem tomou a decisão, a responsabilidade também não é minha"; Doutro lado assiste-se a uma alta concentração do poder; Fortes características de personalismo concomitante com grande tendência a evitar conflitos; A presença da autoridade paternalista concomitante com a postura do espectador e a tendência a evitar conflitos faz com que exista nos liderados frequentemente medo de $\operatorname{errar}^{10}$; Evidencia-se a característica importante da lealdade às pessoas e em contrapartida, da ambiguidade ${ }^{11}$. As decisões muitas vezes não são claras, as regras deixam margem de manobra; Enfim, a flexibilidade, característica fundamental do sistema de ação cultural brasileiro, que representa a capacidade de flutuar nos espaços dos líderes e dos liderados ou do institucional

\footnotetext{
8 O índice IVR não foi medido pela Tanure pois foi representado por Hofstede sucessivamente à publicação do livro Gestão à Brasileira de 2005. ${ }^{9}$ Existe uma diferença entre o valor de LTO exposto pela Tanure (65) e aquele publicado por https://geerthofstede.com/research-and-vsm/dimensiondata-matrix/ (44), sendo esse último o mesmo reportado no livro Cultures and Organizations. Software of the mind. de Hofstede e Minkov.

${ }^{10}$ Tanure identifica este traço evoluindo o modelo anteriormente desenvolvido por ela e Spyer Prates que previa nessa posição a Flexibilidade e que agora passa a ser a característica central do sistema de ação cultural brasileiro (PRATES et al., 1997).

${ }^{11} \mathrm{Na}$ versão de 1997 de Prates e Barros, esta posição era ocupada pelo Formalismo, segundo a Tanure nestes últimos anos consolidou-se o traço cultural de baixa necessidade de lidar com os riscos e as incertezas.
} 
e do pessoal. A flexibilidade tem duas faces, a adaptabilidade e a criatividade. Essa flexibilidade, no sentido da criatividade se manifesta através do famoso jeitinho brasileiro descrito por Damatta (2004) como a forma de navegação social, ou como é definido por Barbosa (1992) é uma forma especial de se resolver algum problema.

Todas estas características são o resultado da interação dos dois eixos estruturantes dos espações culturais: o eixo institucional - pessoal e o eixo dos líderes - dos liderados. O sistema de ação cultural brasileiro explicado por Tanure (2005) pode ser representado da seguinte maneira, pela Figura 4.

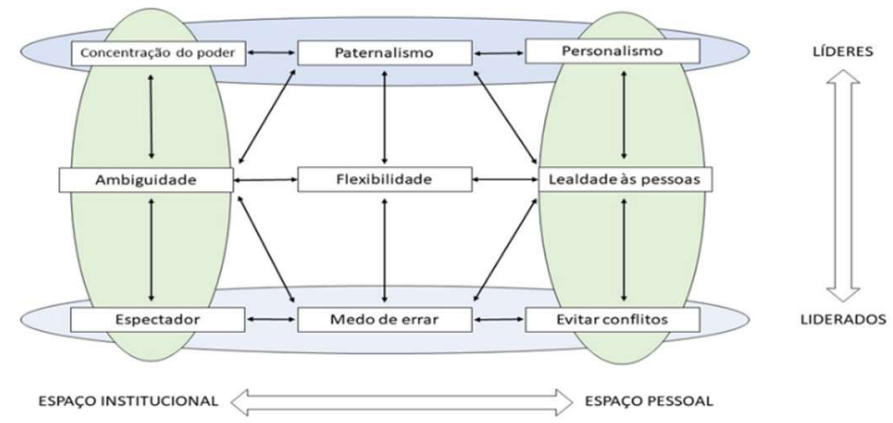

Figura 4: Sistema de ação cultural brasileiro. Fonte: Tanure (2005).

Resulta ser de extrema importância verificar se as características aqui identificadas são favoráveis ou menos em relação àquelas esperadas para a realização eficiente do smart working.

\section{Apresentação dos questionários}

Ao fim de verificar as premissas teóricas apresentadas, foi realizada uma pesquisa qualitativa exploratória do tipo survey aos funcionários de duas plantas (Itália e Brasil) que fazem parte de um grupo multinacional e que começou há alguns meses o caminho da implantação do smart working na própria sede italiana e que está interessado na ampliação deste conceito na filial brasileira.

A pesquisa teve como objetivo a obtenção de dados ou informações sobre características, ações ou opiniões de determinado grupo de pessoas, indicado como representante de uma população alvo, por meio de um instrumento de pesquisa, normalmente um questionário (PINSONNEAULT et al., 1993).

O grupo em objeto atua no setor automotivo, é especializado na área de engenharia, atua como fornecedor de grandes montadoras automotivas e necessariamente respeita altos padrões de segurança e tecnológicos, com grande necessidade de se adaptar às mudanças continuas que os clientes exigem. Tudo isso faz acreditar seja uma realidade bem orientada e estruturada do ponto de vista cultural e infra estrutural para este tipo de desafios.

Do outro lado, as fortes ligações com os clientes, os contatos diretos e contínuos com os vários setores dos clientes e vínculos estreitos entre profissionais aparentemente obstaculizaria o processo de remotização das atividades desenvolvidas.

No momento em que a coleta de dados da pesquisa foi realizada, entre o dia 2 de maio de 2020 e o dia 8 de maio de 2020, todos os funcionários das empresas encontravam-se em regime de home office ou de férias devido às medidas de distanciamento social que a Itália e o Brasil tomaram por causa da pandemia do 
COVID-19. Para conseguir a comparação dos resultados das duas empresas foram postas as mesmas vinte questões, em português e em italiano e utilizando a mesma plataforma eletrônica de coleta de dados.

\section{METODOLOGIA}

Para dar fundamento aos conceitos apresentados neste trabalho, foi realizada uma pesquisa bibliográfica sobre os descritivos de smart working, trabalho remoto, home office e teletrabalho, além de cultura organizacional e a atual normativa vigente nos Países onde foi ambientado o estudo de caso, cuja finalidade, segundo Marconi et al. (2002) é colocar o pesquisador em contato direto com tudo o que foi escrito, dito ou filmado sobre determinado assunto. Portanto, a pesquisa foi realizada ampliando quanto mais possível as fontes bibliográficas. Já pelo fato de representar uma análise de um fenômeno entre dois países diferentes, a busca de fontes foi estendida em ambas as áreas. As palavras-chave utilizadas para a busca bibliográfica foram as seguintes: smart working; trabalho ágil; trabalho remoto; cultura organizacional; gestão empresarial; diferenças culturais e a correspondentes palavras-chaves em língua italiana. 0 levantamento bibliográfico do objeto de estudo abrangeu um período correspondente ao período de 1993 a 2020 em relação aos conceitos de smart working e suas derivações em repositórios acadêmicos nacionais e internacionais. Foram consultadas entre outras as seguintes bases de dados: biblioteca pecege, Scielo, Academia edu, docero, osservatori (observatório de digital transformation do Politécnico de Milão), agendadigitale, periódicos e jornais nacionais italianos e brasileiros, assim como revistas e sites especializados ${ }^{12}$.

As fontes de dados obtidas nesta pesquisa bibliográfica se compõem principalmente por livros, físicos e em formato digital, recorte de artigos em periódicos e jornais nacionais e revistas especializadas, publicações de entidades nacionais e de fundações nacionais e europeias.

Não obstante à escassez de estudos primários relativos ao tema, foi realizada uma revisão sistemática dos documentos obtidos com a intenção de selecionar as fontes mais relevantes. Segundo Guanilo et al. (2011), a revisão sistemática é uma metodologia rigorosa proposta para identificar os estudos sobre um tema em questão, aplicando métodos explícitos e sistematizados de busca, além de avaliar a qualidade e validade desses estudos, assim como sua aplicabilidade.

Resultaram selecionadas as seguintes fontes: • Quatro atos normativos italianos e brasileiros quais: Lei, Medida Provisória, Legge Ordinaria e Decreto del Presidente del Consiglio dei Ministri; • Dez livros: principalmente referentes à organização empresarial e cultura organizacional; • Três artigos científicos; • Publicações de outra natureza quais, entre outras: recorte de revistas especializadas, publicações de Fundações Europeias, publicações de observatórios Universitários e de escolas de alta formação de Ordens profissionais.

Durante a realização deste trabalho, devido à pandemia de COVID-19, houve uma aceleração maciça na difusão em nível global do teletrabalho. Portanto, a relevância do tema extrapolou a fundamentação

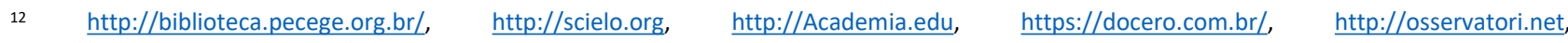
https://www.agendadigitale.eu/ 
teórica e exigiu um refinamento pragmático do paradigma original, devido à necessidade da transposição teórica e de sua implementação. A matriz italiana já estava experimentando a prática há mais de um ano e planejava estender esta filosofia para as suas filiais estrangeiras. Graças ao impulso da pandemia este interesse aumentou consideravelmente estimulando uma aceleração na difusão ao interno do grupo empresarial objeto do estudo de caso.

O estudo de caso é definido segundo Yin (2001), como uma investigação empírica que investiga um fenômeno contemporâneo dentro do seu contexto da vida real em quanto acredita-se que o fenômeno do trabalho ágil é altamente ligado e pertinente ao contexto empresarial, ambiental e cultural onde as empresas operam. Dessa forma, a triangulação dos dados desta pesquisa reforçou o estudo do fenômeno, graças aos questionários enviados para os funcionários da empresa, de onde foi possível extrair um novo modelo de gestão desejável para a aplicação eficaz do trabalho ágil.

Os dois questionários propostos aos funcionários das duas empresas, um em língua italiana e o outro em língua portuguesa, são compostos de vinte questões absolutamente idênticas. A adesão foi voluntária, garantindo-se absoluto sigilo na identificação dos aos respondentes. A adesão voluntária e anônima encontrou participação na matriz italiana de cerca de $80 \%$ da população (115 colaboradores), tendo captado uma amostra de 92 respostas. Já na filial brasileira a população objeto dos questionários é de 66 funcionários, sendo estes a totalidade dos funcionários ativos no momento da pesquisa. Obteve-se 42 respostas, correspondente a $64 \%$ de retorno.

\section{RESULTADO E DISCUSSÃO}

As primeiras quatro questões têm caráter de análise demográfica da amostra analisada. Percebe-se uma preponderância mais marcada na empresa brasileira de colaboradores jovens, entre 26 e 45 anos. Na empresa italiana a curva de distribuição aparece mais plana, veja Figura 5. A componente feminina na empresa italiana é maior, é correspondente a quase três vezes em termos percentuais $(18,5 \%)$ do percentual brasileiro (7,1\%), veja Figura 6.

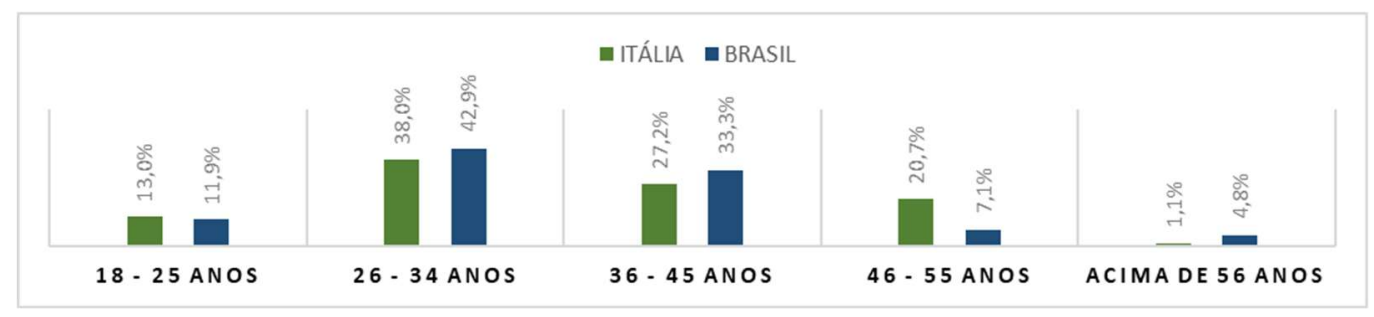

Figura 5: Classes de idade dos entrevistados.

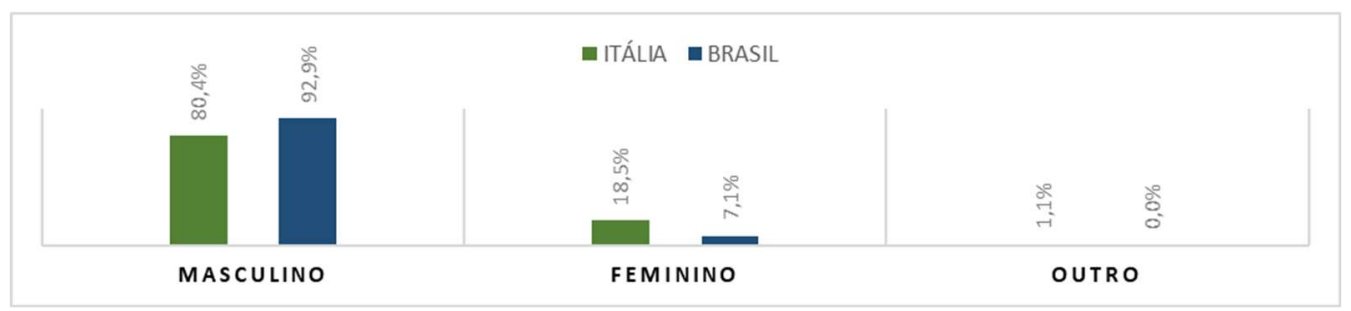

Figura 6: Gênero dos entrevistados. 
Percebe-se uma grande diferença no nível de escolaridade: foram padronizados os níveis compativelmente com as diferenças nos modelos de instrução nos dois países. Uma boa parte das escolas italianas de ensino médio são profissionalizantes não sendo necessária nenhuma especialização sucessiva para obter-se um título útil para o trabalho. Portanto é evidente como no Brasil a grande maioria tem que alcançar um nível de instrução superior para encontrar uma profissão, veja Figura 7. A distribuição de funcionários com filhos pequenos entre as duas empresas é muito parecida em termos percentuais, veja Figura 8.

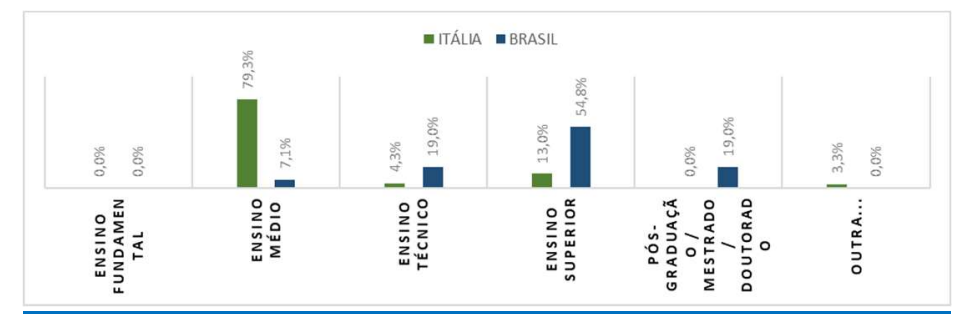

Figura 7: Nível de escolaridade dos entrevistados.

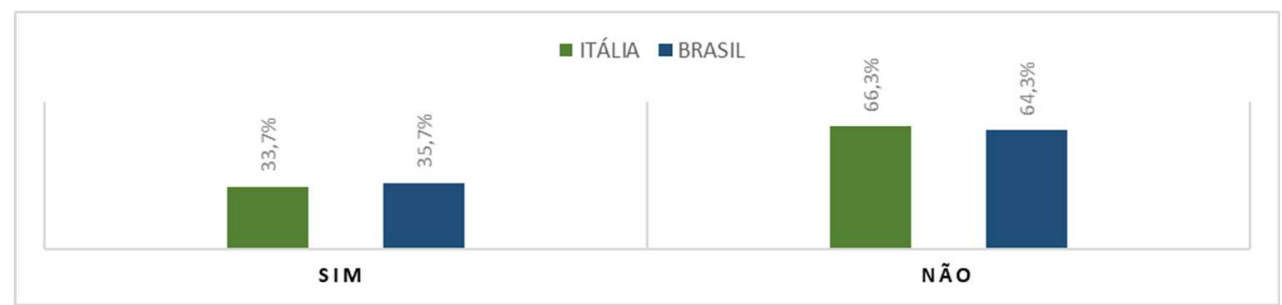

Figura 8: Com/sem filhos menores.

Uma observação relevante sobre estes dados é que uma parte dos funcionários operacionais (projetistas, desenhistas, etc.) da empresa brasileira durante o período do questionário se encontrava de férias devido à parada de algumas atividades a causa da pandemia de COVID-19 por isso que a percentual de retorno dos questionários estava inferior àquela italiana. Esta ausência fez com que a percentual de composição dos operacionais brasileiros fosse inferior àquela dos homólogos italianos, sendo estas proporções muito parecidas em períodos de atividade normal, veja Figura 9.

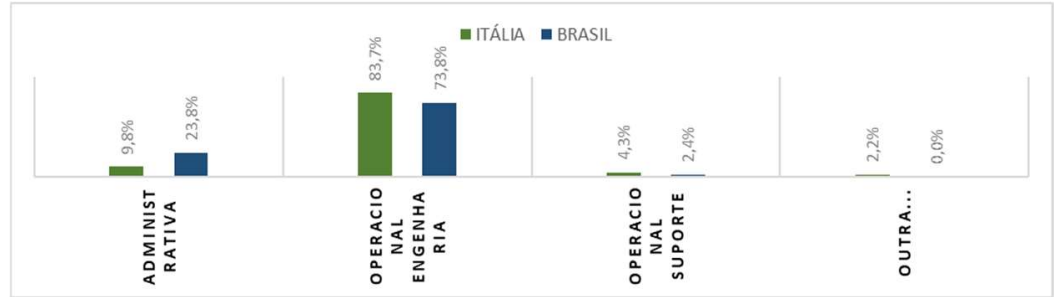

Figura 9: Área de atuação dos entrevistados.

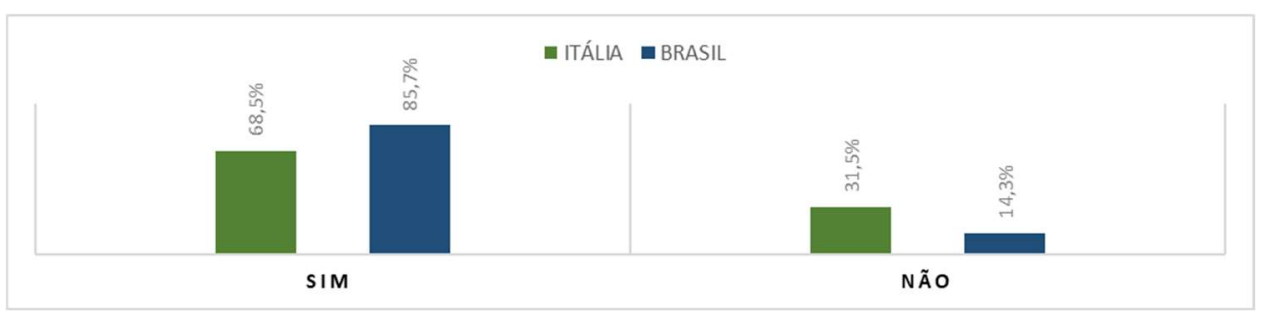

Figura 10: Percentual atual dos trabalhadores em smart working.

Dadas as premissas já evidenciadas anteriormente relativas ao fato que parte dos funcionários da 
empresa brasileira encontravam-se de férias e consequentemente não em regime de Smart working, objetiva-se como a situação emergencial da pandemia de COVID-19 foi de enorme impulso para atuação das medidas de trabalho remoto.

A Figura 10 representa a percentual dos trabalhadores que atualmente estavam em regime de smart working. A Figura 11 representa a percentual dos trabalhadores que experimentaram o smart working antes está emergência do COVID-19. A Figura 12 representa o retorno dos entrevistados sobre a qualidade do trabalho.

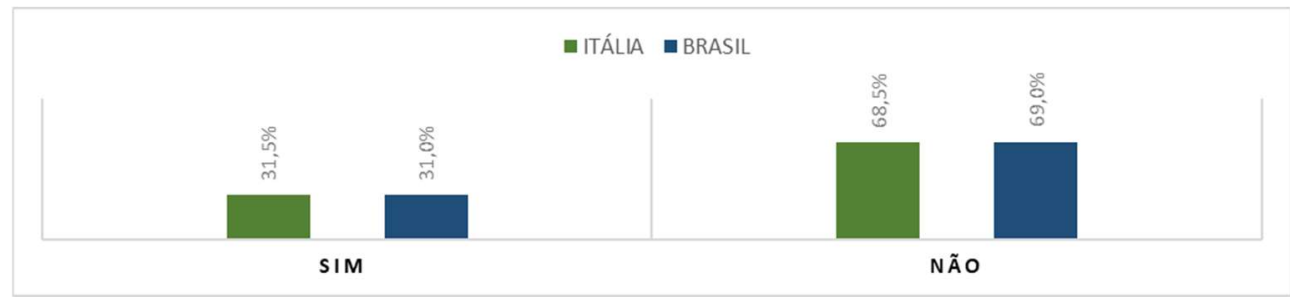

Figura 11: Percentual dos trabalhadores em smart working anteriormente ao COVID-19

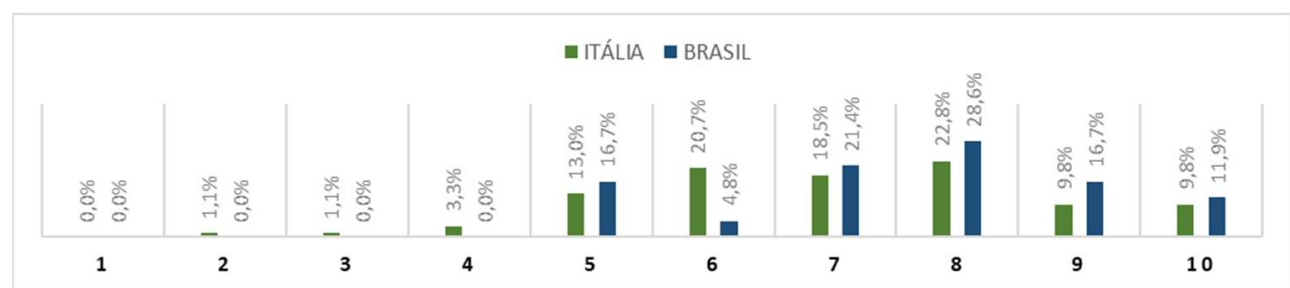

Figura 12: Evolução da qualidade de trabalho (como você considera que a qualidade do seu trabalho mudou em relação à antes - trabalho no escritório?).

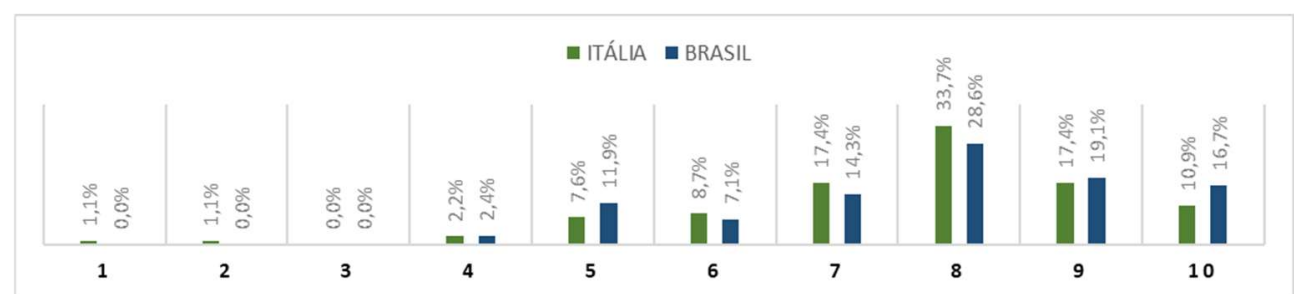

Figura 13: Evolução da produtividade de trabalho (Como você considera a sua produtividade trabalhando na modalidade smart working em relação à modalidade tradicional presencial?).

A Figura 13 representa o retorno dos entrevistados sobre a produtividade do trabalho. A representação do retorno dos entrevistados sobre a independência no trabalho é apresentada na figura 14. A Figura 15 que representa o retorno dos entrevistados sobre a confiança no trabalho. A Figura 16 que representa o retorno dos entrevistados sobre a qualidade na comunicação no trabalho. A Figura 17 que representa o retorno dos entrevistados sobre a capacidade dos líderes.

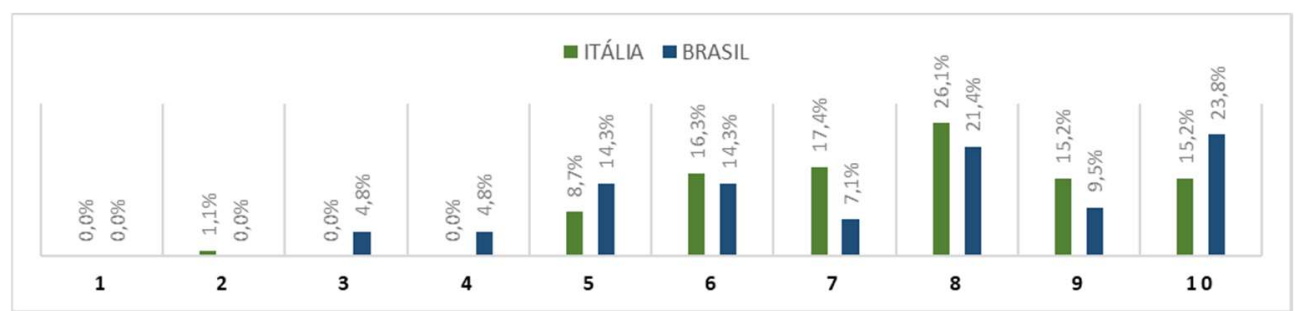

Figura 14: Evolução da percepção de independência no trabalho (Trabalhar em smart working fez com que você se sentisse mais autônomo e independente?). 


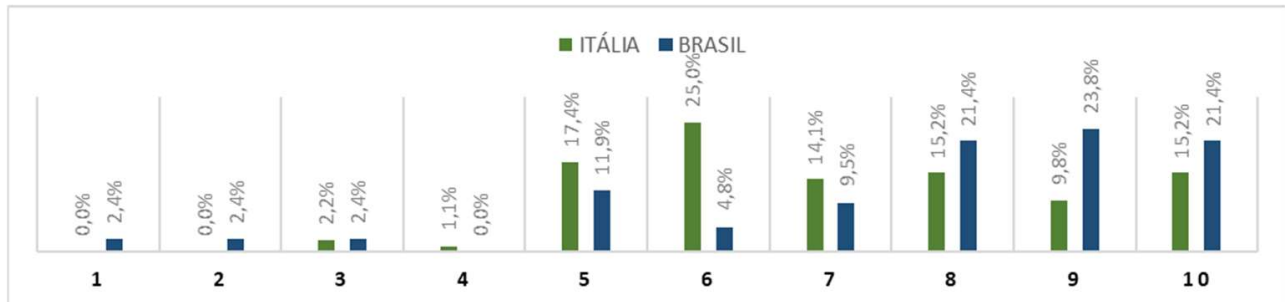

Figura 15: Evolução da percepção da confiança com os colegas de trabalho (Como você considera que o relacionamento com seus colegas/líderes mudou em termos de confiança?).

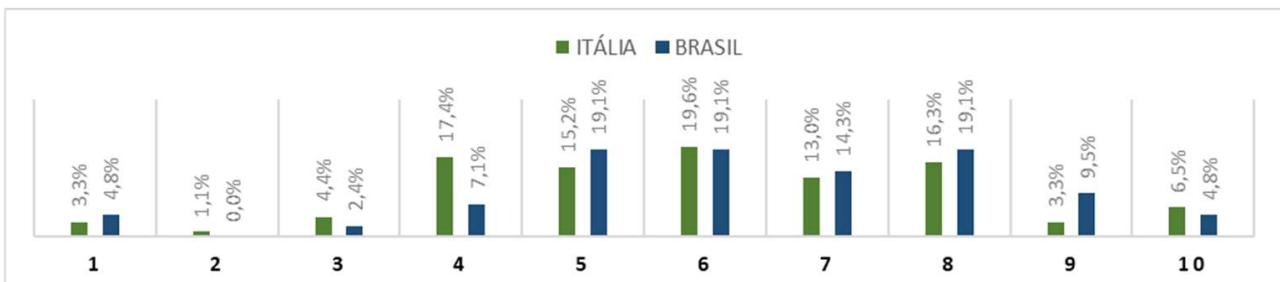

Figura 16: Evolução da qualidade da comunicação com os colegas de trabalho (Como você vê a mudança na qualidade de comunicação entre seus colegas usando a modalidade smart working em relação à modalidade tradicional no escritório?).

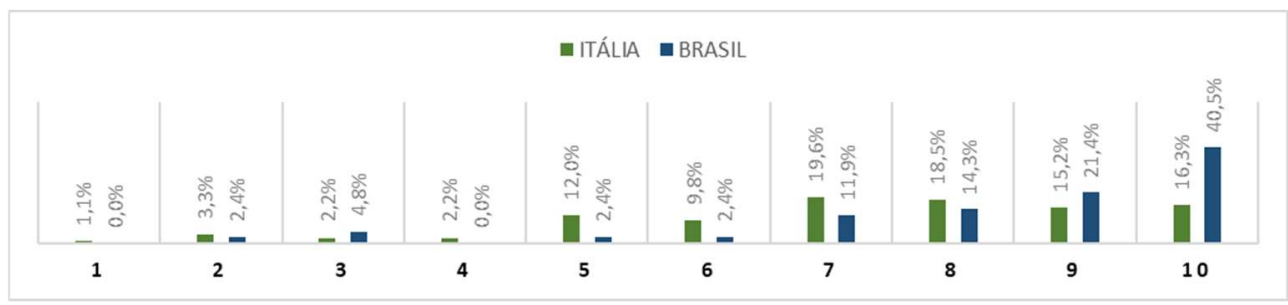

Figura 17: Percepção da capacidade de administração dos líderes (O (s) seu (s) líder (es) tem sabido administrar esta nova modalidade de trabalho?).

Os resultados desta série de questões são analisados na Tabela 2, que representa a frequência das respostas agregando as respostas da seguinte forma: 7 - 10: amplamente positivo; $5-6$ : não totalmente satisfeito; 1 -4: amplamente negativo.

Tabela 2: Frequência nas questões 8, 9,10, 11, 12 e 13 nas duas empresas.

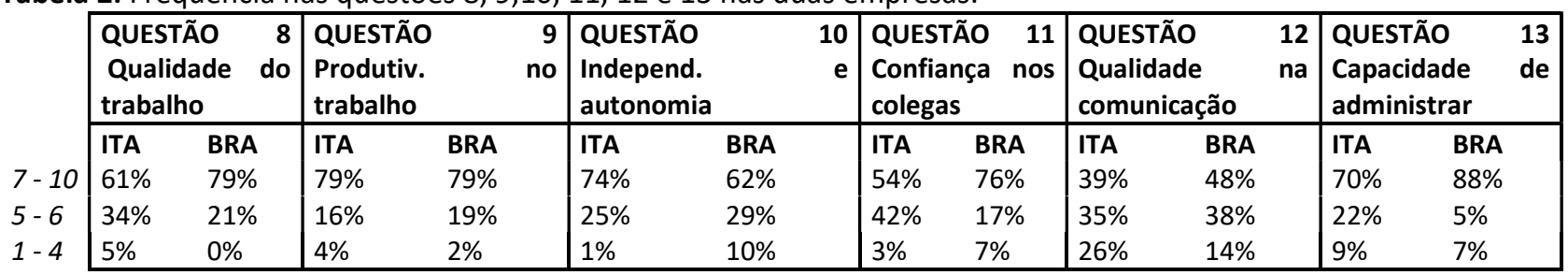

Em quase todas as questões a ampla maioria dos entrevistados demonstrou satisfação na experiência de trabalho à distância. É importante destacar a criticidade do resultado da questão 12 sobre a qualidade da comunicação, pois emerge em ambas as empresas que a maioria dos entrevistados não foi amplamente satisfeita indicando que seria desejável um esforço especial para gerenciar mudança radicais de modalidade de trabalho, através de novas formas de comunicação, de compartilhamento das informações em todos os níveis hierárquicos.

As ferramentas utilizadas são muito parecidas em ambas as empresas e destaca-se um percentual maior de utilização de plataformas de mensagens instantâneas no Brasil e de contatos formais através de email na Itália, veja Figura 18. 


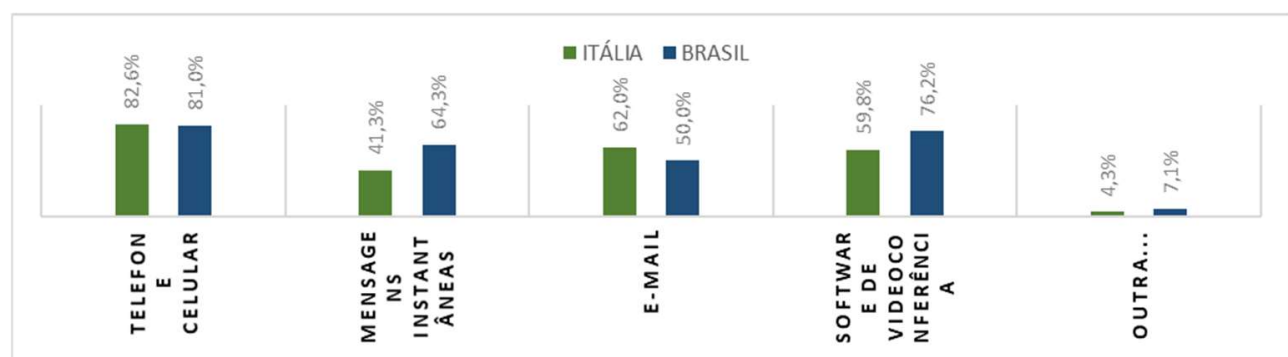

Figura 18: Ferramentas utilizadas na comunicação (Com quais ferramentas você se comunicou principalmente com seus líderes?).

A questão 15 Como o(s) seu(s) líder(es) poderiam ter melhorado a comunicação?, foi uma questão aberta e não obrigatória, porém muitos entrevistados quiseram deixar um comentário. Pode-se destacar os seguintes pontos:

Na matriz italiana, pede-se maior proximidade através da organização de reuniões com utilização de vídeo semanais, uma comunicação mais eficaz dos líderes e maior acompanhamento nas tarefas diárias. Já na filial brasileira, boa parte dos comentários foram voltados a elogiar a capacidade de comunicação da empresa com os funcionários. Em ambas unidades houve uma grande apreciação das ferramentas disponibilizadas, veja Figura 19.

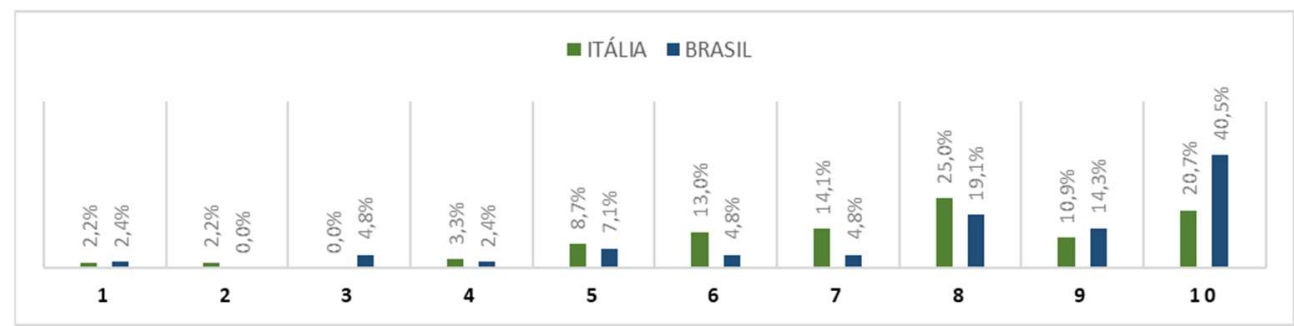

Figura 19: Percepção da qualidade das ferramentas utilizadas (As ferramentas de trabalho que foram disponibilizadas pela empresa são suficientes para que você desenvolva suas atividades?).

Foi posta a questão 17 De quais ferramentas/ aplicativos você sentiu mais necessidade? Para entender onde eventualmente houve necessidade de algumas ferramentas especificas. Em ambas unidades se sentiu falta algumas vezes de: (a) um bom notebook; (b) periféricos quais monitor maior, impressora, scanner; (c) boa conexão internet; (d) celular.

As preferências, seja nas vantagens seja nas desvantagens, são bem parecidas. Nas vantagens observa-se uma preferência na ausência de gastos de transporte para os italianos (na Itália normalmente o transporte não é oferecido pela empresa sendo totalmente de responsabilidade do trabalhador) e de aumento de produtividade para os brasileiros, veja Figura 20.

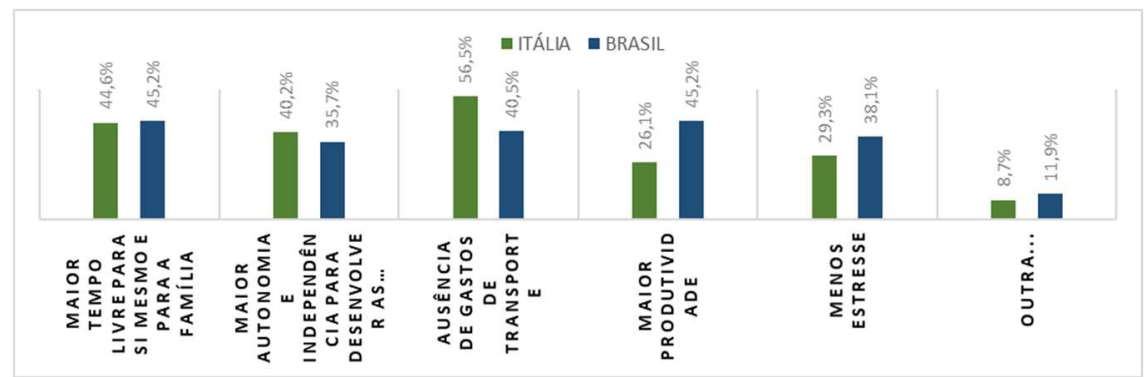

Figura 20: Vantagens do trabalho em smart working (Quais foram, na sua opinião, as maiores vantagens com o trabalho na modalidade smart working?). 
Entre as desvantagens apontadas pela pesquisa mais do dobro (em termos percentuais) dos brasileiros veem a maior responsabilidade como um aspecto negativo. Em outras desvantagens sinteticamente observa-se, para os italianos, a faltas de relacionamento humano, a dificuldade de comunicação e para os brasileiros, a falta de proximidade, os relacionamentos humanos, a comunicação e alguns problemas técnicos, veja Figura 21

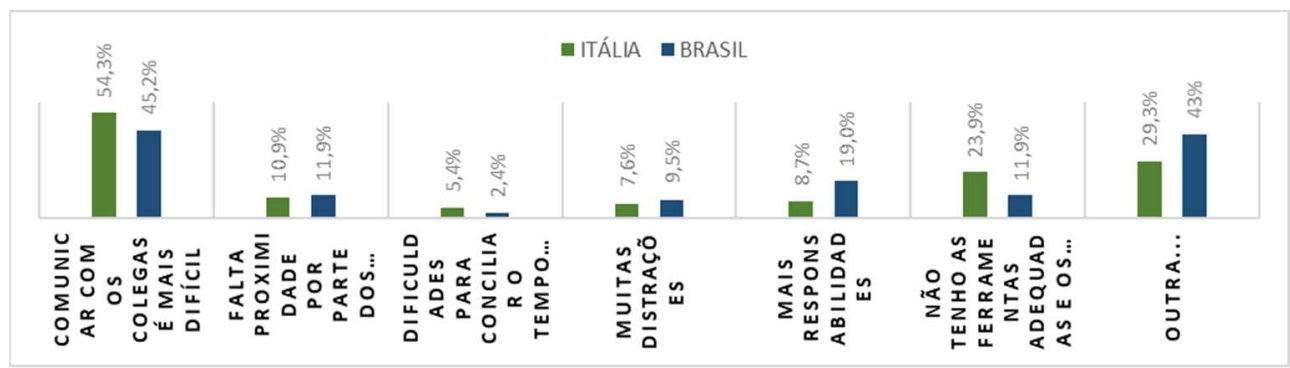

Figura 21: Desvantagens do trabalho em smart working (Quais foram, na sua opinião, as maiores desvantagens com o trabalho na modalidade smart working?).

Nitidamente observa-se que o maior percentual dos italianos quer continuar o regime de trabalho em Smart working após este período emergencial, veja Figura 22.

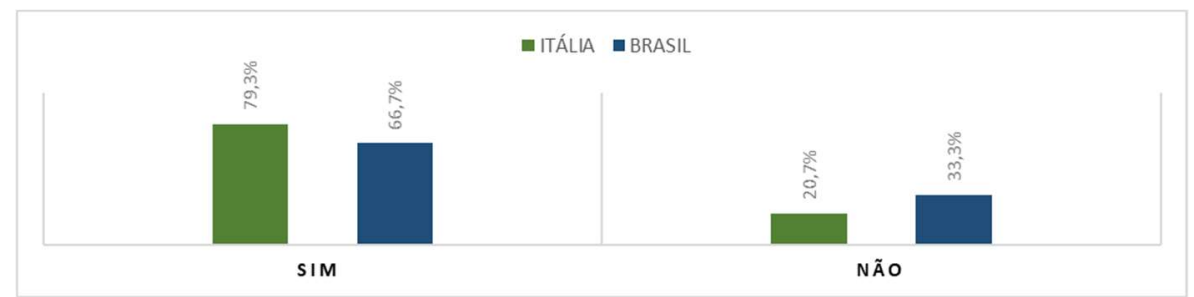

Figura 22: Percentual de pessoas querendo continuar com o smart working (Terminado este momento de emergência, você gostaria de continuar a trabalhar na modalidade smart working?).

Este estudo não quer ser absolutamente exaustivo a ponto de esgotar o assunto, mas simplesmente, representar um estudo de caso de uma empresa que quer inovar e trazer ao Brasil ferramentas, modalidades e filosofias de gestão inovadoras. Portanto, os resultados apresentados não podem ser generalizados ou extrapolados a outros casos.

Observa-se que, embora haja grandes dificuldades encontradas, principalmente devido ao fato de não ser possível planejar com o tempo necessário um percurso gradual de implantação do smart working, uma resposta amplamente positiva.

Vale a pena ressaltar alguns detalhes surgidos da pesquisa: o primeiro é que não se encontrou uma correlação forte entre a idade dos entrevistados e as respostas obtidas. As várias gerações representadas pela amostra analisada tiveram retornos muito homogêneos em todas as questões. Sobre a relação entre os entrevistados com filhos menores (Questão 4) e a eventual vontade de continuar em regime de smart working no futuro (Questão 20), houve reações contrastantes. A amostra italiana mostrou uma reação muito positiva, 27 dos 30 entrevistados (igual a 90\%) com filhos menores demostraram vontade de continuar em regime de smart working. Isso confirma o que se prevê em relação às vantagens potenciais do smart working, ou seja, o smart working traz uma ajuda concreta na harmonização dos tempos de trabalho e de família. Por outro lado, a amostra brasileira se mostrou em contra tendência, com uma reação positiva de somente 6 
pessoas das 15 com filhos menores (igual a 40\%), percentual inferior à média amostral (igual a 66,7\%). Provavelmente não teve a possibilidade por parte dos brasileiros de se acostumar com esta nova modalidade e aproveitar da própria presença em casa.

O nível de satisfação dos funcionários em ambas as empresas em geral foi muito bom. A única questão que não obteve um resultado satisfatório se refere à qualidade da informação entre as pessoas (Questão 12). A falta de presença física no lugar de trabalho deve ser compensada com uma maior e melhor atividade em termos de circulação das informações, por exemplo através de uma maior frequência de reuniões virtuais. É muito provável que os gestores de ambas as empresas deveram se esforçar particularmente para cobrir estas necessidades, pois a tecnologia disponível não falta, será somente necessário trabalhar na eficácia da comunicação.

O smart working é uma filosofia de organização que envolve todos os níveis da empresa e demanda uma mudança radical dos clássicos paradigmas de trabalho. O smart working traz novos conceitos referentes ao tempo, a modalidade e ao lugar de trabalho na empresa e, portanto, faz-se necessário tempo e organização para sua realização de forma concreta e eficaz. $\mathrm{O}$ trabalho remoto é um componente importante do smart working, é com certeza o mais aparente e é muito impactante para a organização da empresa.

Contudo, resulta-se a importância de analisar a reação dos funcionários e das unidades binacionais, objeto de estudo, a esta forma de trabalho fora da empresa, como parte do processo mais amplo de transformação.

Observando mais profundamente os conceitos da filosofia do smart working e relacionando-os com o ambiente normativo brasileiro descrito, pode-se fazer algumas observações. Acredita-se desejável que o sistema normativo favoreça mais a liberdade nas contratações entre as partes. Seria oportuno que seja deixada máxima autonomia às partes de estabelecer lugar e tempos de execução de trabalho. Além disso, trabalhar em smart working significa trabalhar por objetivos, o computo das horas trabalhadas perde totalmente de sentido, provavelmente seria interessante que as partes possam ter a liberdade de acordar formas diferentes de remuneração do trabalho. Passar ao smart working significa rever a relação entre os trabalhadores, os gestores e as empresas. O que comporta favorecer uma mudança radical nas culturas organizacionais. Neste caso a empresa matriz adota uma abordagem etnocêntrica com a sua filial brasileira, com a finalidade de compartilhar os mesmos valores, corroborando com os fundamentos de cultura organizacional descritos por Robbins et al. (2011).

Não foi o intuito de se exaurir neste estudo o amplo trabalho de pesquisa, análise e implementação do smart working. Sugere-se, como proposta para futuras pesquisas complementares, a análise dos aspectos relacionados à privacidade de dados nesta nova forma de organização, especialmente em relação à nova lei de proteção de dados (LGPD) em vigor.

\section{CONCLUSÕES}

Os resultados obtidos no estudo foram positivos. A empresa e os funcionários brasileiros reagiram com eficácia às mudanças. Isto faz que existam boas possibilidades de sucesso neste processo para a 
realização completa do smart working. No entanto a confiança está na base da estrutura, o que comporta o abandono de algumas características típicas brasileiras presentes na cultura organizacional: (a) os líderes serão estimulados a perder o paternalismo, abandonar a visão de concentração do poder a favor de umas atitudes mais voltadas à colaboração, ao compartilhamento dos objetivos e das responsabilidades. O papel dos líderes passaria a ser aquele de ponto de referência para os colegas, aquele que confia nos colaboradores e que compartilha decisões; (b) os liderados serão solicitados a perder o medo de errar, a abandonar a postura do espectador em favor de atitude mais proativas, terão a autonomia necessária para se organizar. Em prática, os líderes confiam neles e eles confiam nos líderes, veja o modelo precedentemente apresentado nos resultados.

\section{REFERÊNCIAS}

BARBOSA, L.. O Jeitinho Brasileiro: a arte de ser mais igual que os outros. Rio de Janeiro: Campus, 1992.

BRASIL. Lei n. 13.467, de 13 de julho de 2017. Altera a Consolidação das Leis do Trabalho [CLT], aprovada pelo Decreto-Lei no 5.452, de 10 de maio de 1943, e as Leis nos 6.019, de 3 de janeiro de 1974, 8.036, de 11 de maio de 1990, e 8.212, de 24 de julho de 1991, a fim de adequar a legislação às novas relações de trabalho. Brasília: DOU, 2017.

BRASIL. Medida Provisória n. 927, de 22 de março de 2020. Dispõe sobre as medidas trabalhistas para enfrentamento do estado de calamidade pública reconhecido pelo Decreto Legislativo no 6, de 20 de março de 2020, e da emergência de saúde pública de importância internacional decorrente do coronavírus (covid-19), e dá outras providências. Brasília: DOU, 2020.

CLAPPERTON, G.; VANHOUTTE, P.. II Manifesto dello Smarter Working. Milano: Libri Este, 2014.

DAMATTA, R.. O que é o Brasil? Rio de Janeiro: Rocco, 2004.

GUANILO, M. C. T. U.; TAKAHASHILL, R. F.; BERTOLOZZI, M. R.. Revisão sistemática: noções gerais. Rev. Escola de Enfermagem USP, v.45, n.5, p.1260-1266, 2011. DOI: http://dx.doi.org/10.1590/S0080-62342011000500033

HARTOG, K. L.; SOLIMENE, A.; TUFANI, G.. The Smart Working Book: L'età del lavoro agile è arrivata. Finalmente!. Roma: Seedble SRL, 2015.

HOFSTEDE, G.; NEUIJEN, B.; OHAYV, D.; SANDERS, G.. Measuring organizational cultures: a qualitative and quantitative study across twenty cases. Administrative Science Quarterly, v.35, n.2, p.286-316, 1990. DOI: https://doi.org/10.2307/2393392

HOFSTEDE, G.; HOFSYEDE, G. J.; MINKOV, M.. Cultures and Organizations: software of the mind. New York: McGraw Hill, 2010.
ITÁLIA. Lei n. 81 de 22 de maio de 2017. Misure per la tutela del lavoro autonomo non imprenditoriale e misure volte a favorire l'articolazione flessibile nei tempi e nei luoghi del lavoro subordinato. Roma: Gazzetta Ufficiale, 2017.

ITÁLIA. DPCM 01 de março de 2020. Ulteriori disposizioni attuative del decreto-legge 23 febbraio 2020, n. 6, recante misure urgenti in materia di contenimento e gestione dell'emergenza epidemiologica da COVID-19. Roma: Gazzetta Ufficiale n.52, 2020.

MARCONI, M.; LAKATOS, E. M.. Técnica de Pesquisa. São Paulo: Atlas, 2002.

PINK, D.. Drive: the surprising truth about what motivates us. New York: Riverheads Books, 2009.

PINSONNEAULT, A.; KRAEMER, K. L.. Survey research in management information systems: an assessment. Journal of Management Information Systems, v.10, n.2, p.75-105, 1993. Dol: https://doi.org/10.1080/07421222.1993.11518001

PRATES, M. A.; BARROS, B.. O estilo brasileiro de administrar: sumário de um modelo de ação cultural brasileiro com base na gestão empresarial. In: MOTTA, F.; CALDAS, M.. Cultura organizacional e cultura brasileira. São Paulo: Atlas, 1997

ROBBINS, S. R.; JUDGE, T. A.; SOBRAL, F.. Comportamento Organizacional: teoria e prática no contexto brasileiro. São Paulo: Pearson Education do Brasil, 2011.

TANURE, B.. Gestão à Brasileira: uma comparação entre América Latina, Estados Unidos, Europa e Ásia. São Paulo: Atlas, 2005

TROMPENAARS, F.. Nas ondas da cultura: como entender a diversidade cultural nos negócios. São Paulo: Educatora, 1993.

YIN, R. K.. Estudo de Caso: planejamento e métodos. Porto Alegre: Bookman, 2001.

A CBPC - Companhia Brasileira de Produção Científica (CNPJ: 11.221.422/0001-03) detém os direitos materiais desta publicação. Os direitos referem-se à publicação do trabalho em qualquer parte do mundo, incluindo os direitos às renovações, expansões e disseminações da contribuição, bem como outros direitos subsidiários. Todos os trabalhos publicados eletronicamente poderão posteriormente ser publicados em coletâneas impressas sob coordenação da Sustenere Publishing, da Companhia Brasileira de Produção Científica e seus parceiros autorizados. Os (as) autores (as) preservam os direitos autorais, mas não têm permissão para a publicação da contribuição em outro meio, impresso ou digital, em português ou em tradução. 